\title{
The Effect of Zinc Supplementationon the Symptoms of Gastroesophageal Reflux Disease; a Randomized Clinical Trial
}

\author{
Afshin Shafaghi ${ }^{1}$, Jalal Hasanzadeh $^{2}$, Fariborz Mansour-Ghanaei $^{3 *}$, Farahnaz Joukar $^{4}$, Maryam Yaseri ${ }^{2}$
}

1. Associate Professor, Gastrointestinal \& Liver Diseases Research Center (GLDRC), Guilan University of Medical Sciences, Rasht, Iran

2. Internist, Researcher, Gastrointestinal Cancer Research Center (GICRC), Guilan University of Medical Sciences, Rasht, Iran

3. Professor, Gastrointestinal \& Liver Diseases Research Center (GLDRC), Guilan University of Medical Sciences, Rasht, Iran

4. PHD by Research Student, Faculty member, Gastrointestinal \& Liver Diseases Research Center (GLDRC), Guilan University of Medical Sciences, Rasht, Iran

\section{* Corresponding Author:}

Fariborz Mansour-Ghanaei, MD

Gastrointestinal and Liver Diseases Research Center (GLDRC), Guilan University of Medical Sciences, Razi Hospital, Sardar-Jangle Ave.Rasht, Iran

P.O. Box: 41448-95655

Tel: +981333535116

Fax: +98133353495

Email: ghanaei@gums.ac.ir

Received: 22 Feb. 2016

Accepted: 07 Jul. 2016

\section{ABSTRACT}

\section{BACKGROUND}

Currently, it has been demonstrated that gastroesophageal reflux disease (GERD) is one of the most important disorders of the digestive system and the commixture of regular diet has a significant influence on its incidence, symptoms, and prognosis. The purpose of this study was to evaluate the effect of zinc supplementation, in combination with PPIs(Proton pump inhibitors), on the improvement of GERD symptoms.

\section{METHODS}

In a randomized double blind clinical trial, patients with reflux symptoms, who had obtained Reflux Disease Questionnaire (RDQ) score more than 8, were included and all the demographic features were recorded. Then, using upper gastrointestinal (GI) endoscopy, all the patientswere divided into two groups as having non-erosive reflux disorder (NERD), or erosive reflux disorder (ERD). At the next step, based on random block statistical method, we divided the two groups into two subgroups; the drug subgroup [treated with PPIs (40 mg pantoprazole/daily), changing life style, and $220 \mathrm{mg}$ zinc capsules daily] and the placebo subgroup [treated with PPIs, changing life style, and placebo]. After 3 months, we analyzed all data and the RDQ questionnaire was filled out for each patient. This project has been registered in Iranian Registry of Clinical Trials (IRCT) and all data were analyzed using SPSS software version 2.

\section{RESULTS}

A total of 140 patients ( 81 women and 59 men) with mean age of $42.78 \pm 11.5$ years were included with 70 patients in each group. The most frequent presentations were heart burn (45.7\%), and acid regurgitation (39.3\%). The RDQ scores decreased after intervention in both drug $(p<0.001)$ and placebo groups $(p<0.001)$, which were statistically significant. But the difference of RDQ scores between the drug group and placebo group was not statistically significant $(\mathrm{p}=0.086)$.

\section{CONCLUSION}

Zinc supplementation cannot improve the severity of GERD.

\section{KEYWORDS}

Gastroesophageal Reflux; Zinc; Symptoms

\section{Please cite this paper as:}

Hasanzadeh J, Shafaghi A, Mansour-Ghanaei F, Joukar F, Yaseri M. The Effect of Zinc Supplementation on the Symptoms of Gastroesophageal Reflux Disease; a Randomized Clinical Trial.Middle East J Dig Dis 2016;8:289-296. DOI: 10.15171/mejdd.2016.38

\section{INTRODUCTION}

One of the chronic and prevalent disorders of the digestive system is gastroesophageal reflux disease (GERD).Reflux of the gastric contents into the esophagus causes troublesome symptoms, including heartburn, 
regurgitation, and esophageal damages. ${ }^{1}$

In population-based studies, a remarkable increase in the incidence of GERD has been reported with the prevalence rates of $10-25 \%$ over the past decades globally. ${ }^{2,3}$ GERD can be classified based on the presence of symptoms without esophageal mucosal breaks on endoscopic examination [nonerosive reflux disease (NERD)] and the progression of NERD to erosive reflux disorder (ERD). ${ }^{1,4}$

Based on many studies, one of the most important risk factors, which are associated with the incidence and symptoms of GERD is human regular nutrition. Several studies have shown that the commixture of regular diet has a significant effect on the incidence, symptoms, and prognosis of GERD. ${ }^{5-7}$

Zinc is one of these critical components of regular diet, which is presented in all human tissues and body fluids (such as cornea, retina, skin, and parietal cells) and has an important role in cellular function. ${ }^{8}$ The effect of this mineral on GERD symptoms still remains unclear. Some studies have presented that zinc effectively inhibits gastric acid secretion, which provides a new prolonged therapy for those who suffer from overproduction of acid associated disorders such as heartburn and gastric acid reflux. ${ }^{9,10}$ On the other hand, there are other surveys that have shown that there is no relationship between acid reflux complications and intake of zinc supplements. ${ }^{11}$ Unfortunately, zinc deficiency is a frequent medical disorder worldwide, and therefore, it is necessary to know if its supplements could really improve the GERD symptoms. In this survey, we decided to evaluate the effect of zinc supplementationon GERD symptoms in patients who referred to gastrointestinal (GI) clinics. If there is a true relationship between zinc intake and improvement of GERD symptoms, this can be a good choice for adding it to routine GERD medical treatment.

\section{MATERIALS AND METHODS}

In this randomized double blind clinical trial, all patients with acid reflux symptoms, referred to gastroenterology clinics in Rasht (a city in the northern Iran) from September 2014 to January 2015, were enrolled. Sampling method was easy and available.
The patients were given the Reflux Disease Questionnaire (RDQ), ${ }^{12}$ for evaluating the symptoms before treatment. The RDQ is a self-administered questionnaire by which patients describe the frequency and severity of their GI symptoms by answering 15 questions scaled as Likert-type with scores ranging from 0 to 5 .

The individuals who obtained a RDQ score less than 8 , patients aged below 18 years, pregnant women, patientswith positive $H$. pylori laboratory test, those with positive history of peptic ulcers, or patients with a history of previous abdominal surgery for any reason, were excluded from the study.

\section{Step-1:}

Using upper GI endoscopy, two equal number groups were formed; 70 subjects with NERDas NERD group and 70 subjects with ERD as ERD group. A checklist based on the demographic features (such as age, sex, medical history, positive history of $\mathrm{H} 2$ blockers or PPIs consumption, duration of disease, more than $10 \mathrm{~kg}$ weight gain after maturity, weight loss during the past 3 months, insomnia, rapid eating, spicy foods, dinner time at 2 hours before sleep, smoking, and alcohol consumption) was filled out for each subject.

\section{Step-2:}

At the next step, based on random block statistical method, we divided each group into two subgroups; the drug subgroup $(n=35)$ [treated with PPIs (40 mg pantoprazole/daily), changing life style, and $220 \mathrm{mg}$ zinc capsules daily], and the placebo subgroup $(n=35)$ [treated with PPIs, changing life style, and placebo] (figure1).

\section{Materials:}

The zinc capsules contained $50 \mathrm{mg}$ pure zinc, which was manufactured in Al-Havy Company. Both patients and the researchers did not know whether who received the drug or who received the placebo and all the patients were coded to prevent bias. After 3 months, we assessed all data and for the second time, RDQ questionnaire was filled out for each patient to evaluate the treatment result. 


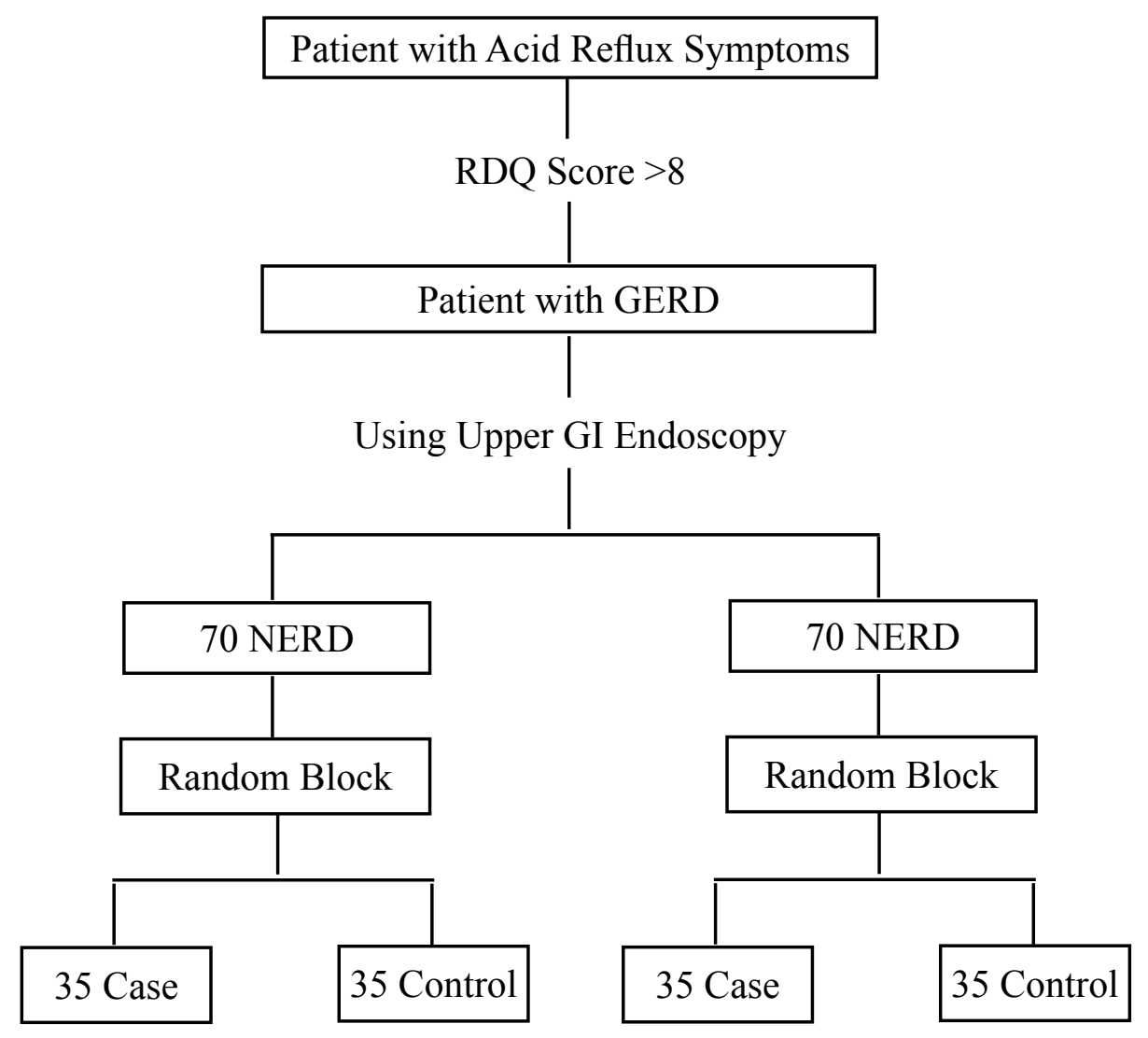

Fig.1: The algorithm of the approach

\section{Ethics and statistics:}

This study was reviewed and approved by the Ethics Committee of Guilan University of Medical Sciences, and written informed consent was obtained from all the participants. Also, this project has been registered in Iranian Registry of Clinical Trials (IRCT registration number: IRCT201305281155N16). All the data were statistically analyzed using SPSS software for windows version 21.0 (SPSS Inc., Chicago, IL, USA). Percentage and frequency were used to report the results of the qualitative data and standard deviation and the mean were used to report the quantitative data. Chi-square, Fisher exact and independent $t$ tests were used to compare the variables. In non-parametric results, Wilcoxon ranks test and Mann-Whitney test were used. $\mathrm{p}<0.05$ was considered as statistically significant.
Of the 140 patients with GERD who were enrolled in this survey, 81 patients were women (55.7\%) and 59 patients were men (44.3\%). The mean age of the subjects was $42.78 \pm 11.5$ years. The most frequent underlying diseases were: Cardiac disease $(n=13)$, diabetes $(n=14)$, hypertension $(\mathrm{n}=13)$, and asthma $(\mathrm{n}=9) .15$ patients were smokers and 8 patients were alcohol consumer. 48 and 81 patients had a history of H2 blockers and PPIs consumption, respectively.

The mean duration between the time of first symptoms presentation and diagnosis was $25.24 \pm 7.8$ months. Heart burn $(\mathrm{n}=64)$, acid regurgitation $(\mathrm{n}=55)$, and retrosternal pain $(n=49)$ were the most frequent GERD presentations. Chart1 shows the general habits of the patients.

Based on random block method, the patients were divided into drug and placebo groups. Of the 70 patients included in the drug group, with mean age of $43.98 \pm 11.5$ years, ${ }^{22}$ patients were men $(31.4 \%)$ and 48 patients were women $(68.6 \%)$. Of the 70 individuals included in the

\section{RESULTS:}




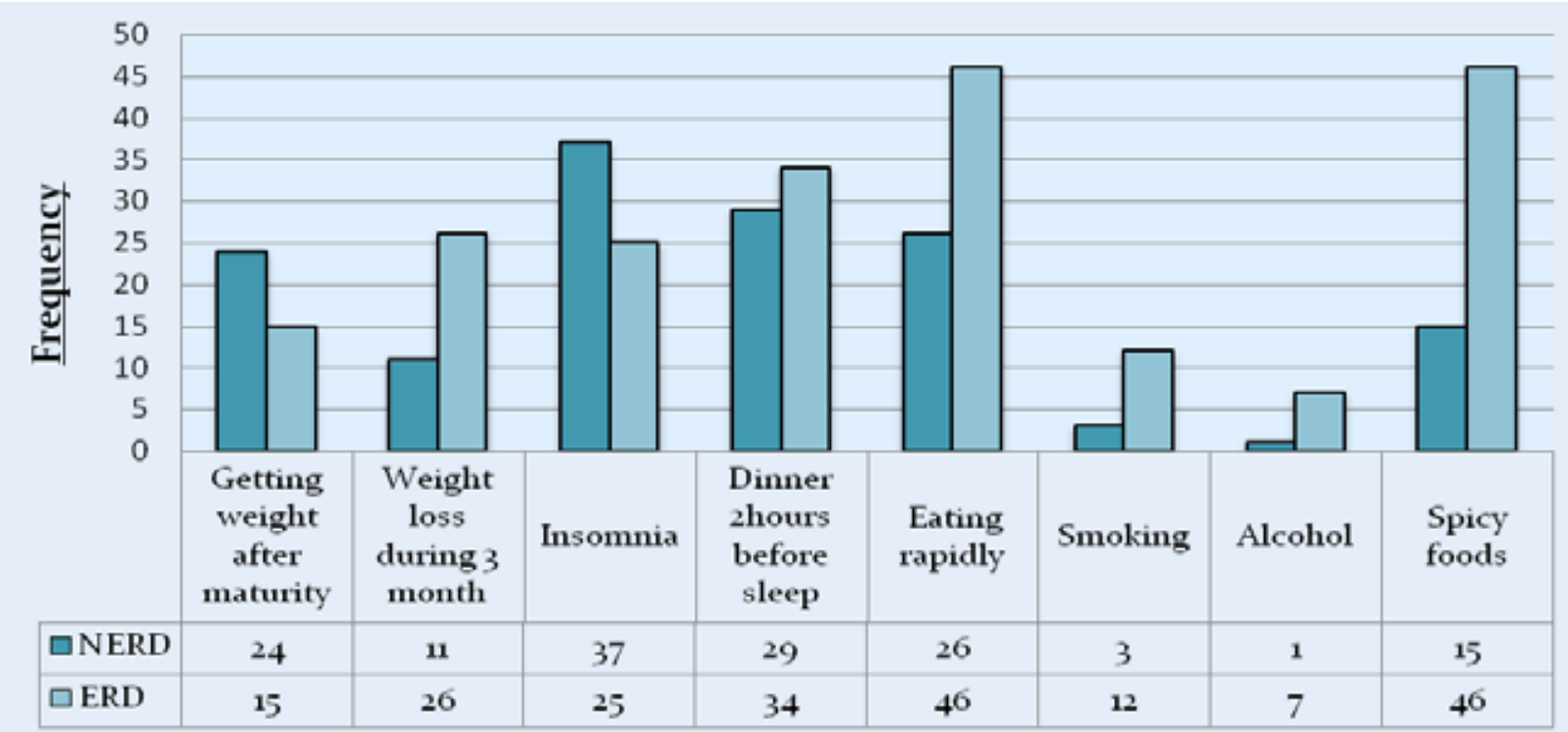

Chart.1: The frequency distribution of the subject's general habits

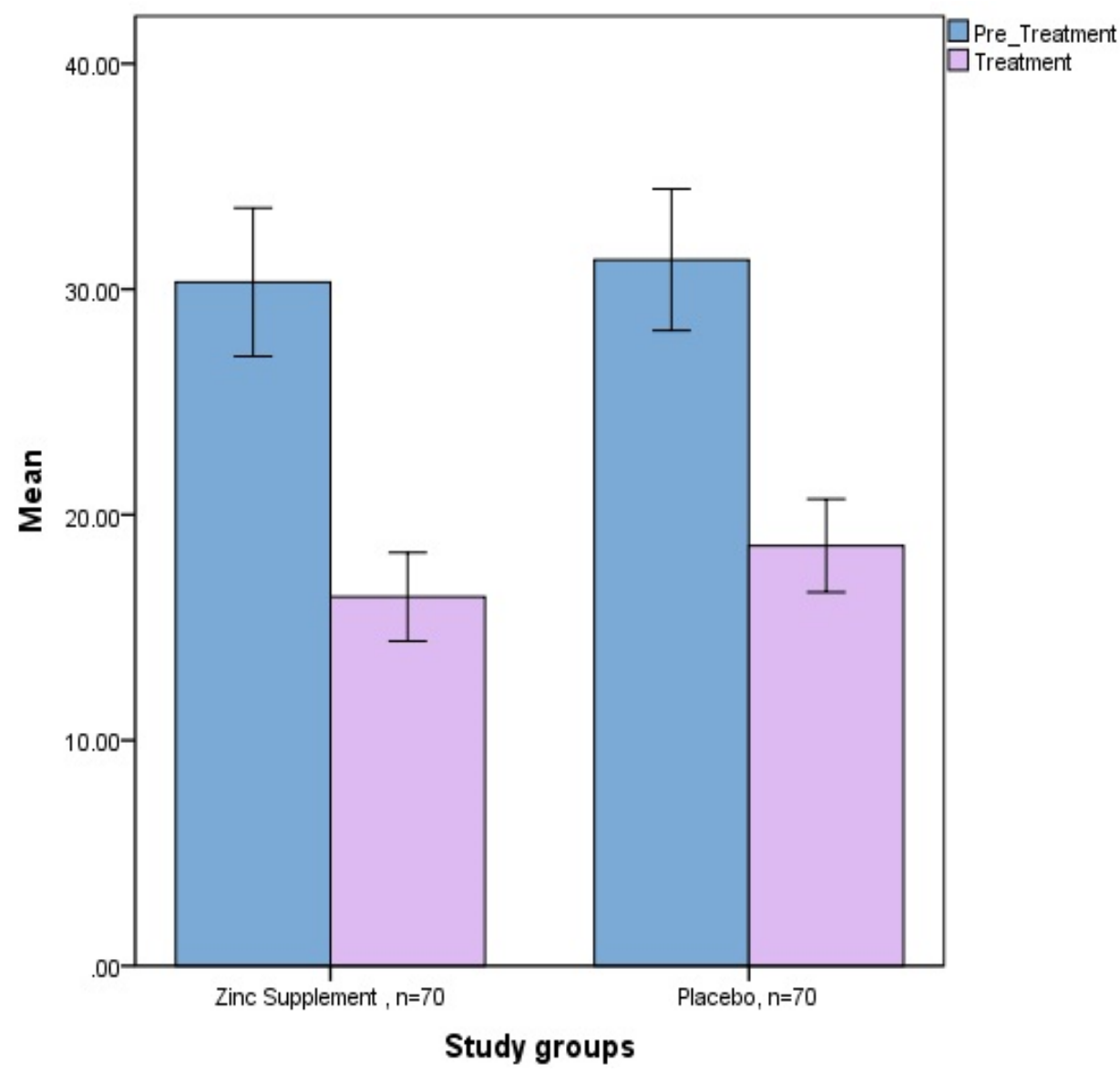

Chart.2: The RDQ scores before and after intervention in both the study groups 
Table1: Comparison of the frequency of GERD presentations among all subjects before and after intervention

\begin{tabular}{|c|c|c|c|c|c|c|}
\hline \multirow[b]{2}{*}{ GERD presentations } & \multicolumn{3}{|c|}{ Drug group $(n=70)$} & \multicolumn{3}{|c|}{ Placebo group $(n=70)$} \\
\hline & $\begin{array}{l}\text { Before } \\
\text { intervention [n } \\
(\%)]\end{array}$ & $\begin{array}{c}\text { After } \\
\text { intervention } \\
{[\mathrm{n}(\%)]}\end{array}$ & $P$ value & $\begin{array}{c}\text { Before } \\
\text { intervention } \\
{[\mathrm{n}(\%)]}\end{array}$ & $\begin{array}{c}\text { After } \\
\text { intervention } \\
{[\mathrm{n}(\%)]}\end{array}$ & $P$ value \\
\hline Chest Pain & $48(68.6)$ & $20(28.6)$ & 0.001 & $49(70)$ & $29(41.4)$ & 0.001 \\
\hline Regurgitation & $49(69.9)$ & $21(30)$ & 0.001 & $48(68.6)$ & $21(30)$ & 0.002 \\
\hline Throat pain & $43(61.4)$ & $12(17.1)$ & 0.002 & $30(42.9)$ & $13(18.6)$ & 0.004 \\
\hline Hoarseness & $46(65.7)$ & $11(15.7)$ & 0.003 & $30(42.9)$ & $12(17.1)$ & 0.003 \\
\hline Throat cleansing & $54(77.1)$ & $15(21.4)$ & 0.002 & $54(77.1)$ & $24(34.3)$ & 0.002 \\
\hline Sore throat & $30(42.9)$ & $5(7.1)$ & 0.001 & $20(28.6)$ & $6(8.6)$ & 0.001 \\
\hline Chronic cough & $50(71.4)$ & $12(17.1)$ & 0.001 & $44(62.9)$ & $26(37.1)$ & 0.001 \\
\hline Dysphagia & $19(27.8)$ & $3(4.3)$ & 0.002 & $18(25.8)$ & $7(9.9)$ & 0.007 \\
\hline Postnasal drip & $51(72.8)$ & $20(28.6)$ & 0.001 & $50(71.5)$ & $35(50)$ & 0.003 \\
\hline Foreign body sensation & $43(61.4)$ & $12(17.1)$ & 0.002 & $52(74.2)$ & $27(38.5)$ & 0.001 \\
\hline Burning tongue & $17(24.2)$ & $1(1.4)$ & 0.003 & $11(15.8)$ & $3(4.3)$ & 0.03 \\
\hline Throat tightness & $20(28.6)$ & ---- & 0.002 & $14(20)$ & $3(4.3)$ & 0.003 \\
\hline Otitis media & $11(15.7)$ & ---- & 0.001 & $91(12.9)$ & $2(2.8)$ & 0.02 \\
\hline Insomnia & $29(41.4)$ & $9(12.9)$ & 0.001 & $23(32.9)$ & $5(7.1)$ & 0.001 \\
\hline Heart burn & $64(91.4)$ & $23(31.4)$ & 0.002 & $57(81.4)$ & $32(45.7)$ & 0.002 \\
\hline
\end{tabular}

Table 2: Responsiveness indicators by zinc supplementation and placebo treatment

\begin{tabular}{ccccc}
\hline \multirow{2}{*}{ RDQ Score } & \multicolumn{2}{c}{ Effect Size } & \multicolumn{2}{c}{ Standardized response mean } \\
\cline { 2 - 5 } & Drug group & Placebo group & Drug group & Placebo group \\
\cline { 2 - 5 } & 1.24 & 1.14 & 0.75 & 0.78 \\
\hline
\end{tabular}

placebo group, with mean age of $41.48 \pm 12.4$ years, 37 patients were men $(52.9 \%)$ and 33 patients were women (47.1\%).

The statistical distribution of age and sex between the two groups had normal distribution. Statistical analysis showed no direct relationship between the results in the groups and age, sex, and general habits. Among underlying diseases, $4.3 \%$ of patients in the drug group and $14.3 \%$ of the patients in placebo group suffered from high blood pressure, and $20 \%$ of the patients in the drug group and $48.6 \%$ of the patients in the placebo group mentioned a history of $\mathrm{H} 2$ blockers consumption. But other underlying diseases such as diabetes, asthma, cardiovascular disease, and use of PPIs did not show significant difference. Tablel shows the difference of the frequency of GERD presentations, before and after intervention, among all the subjects. As table shows, the frequency of presentations decreased in both drug and placebo groups after treatment. Based on the results obtained byFisher's exact test, the statistical difference between the drug and placebo groups in terms of presentations' frequencies was statistically significant in 6 items: Throat cleansing $(p=0.05)$, chronic cough $(p=0.04)$, postnasal drip ( $p=0.03)$, foreign body sensation $(p=0.003)$, heart burn ( $p=0.003)$, and otitis media $(p=0.003)$.

Based on K-S test, RDQ scores did not follow the normal statistical distribution pattern. So to compare the results, before and after treatment, in each group and between the both groups, we used Wilcoxon ranked test and Mann-Whitney test, respectively (chart 2). As the chart shows, the RDQ scores decreased after intervention in both drug group $(p<0.001)$ and placebo group $(p<0.001)$, which were statistically significant. On the other hand, based on Mann-Whitney test, the difference of RDQ scores between the drug group and placebo group was not statistically significant $(p=0.086)$. To 
analyze the treatment effect, we assessed the effect size, which based on Cohen's classification, ${ }^{13}$ showed a large difference after treatment $(0.8)$ as a proper influence on each group. But the comparison of standard response between the two study groups was not significant $(p=0.72)$. These results show that due to pantoprazole, RDQ score decreased in both groups but zinc supplementation could not make a huge different results in drug group (table 2).

\section{DISCUSSION:}

GERD is elucidated as symptoms or mucosal damages processed by the abnormal reflux of gastric contents into the esophagus. ${ }^{14}$ Affecting $33 \%$ of the world's populace, GERD incurs noteworthy immediate and backhanded expenses, huge loss of profitability of the affected individuals, and irreversible impacts on the quality of life. ${ }^{15}$ Due to the importance of GERD, design of more studies to identify its different aspects could be an effective task in the improvement of the general health.

Our findings showed that heart burn, acid regurgitation, and retrosternal pain are the most frequent symptoms of GERD, which is similar to other surveys. ${ }^{16,17}$ This shows that when a patient presents with such symptoms, we have to consider GERD as the most important differential diagnosis and should refer him to a gastroenterology clinic.

One of the most important risk factors thathave appeared to be connected with the side effects of gastroesophageal reflux is the mixture of daily nutrition. ${ }^{15-16}$ Our results showed that the highest frequency of general habits in patients with GERD belonged to rapid eating and eating spicy foods. Today, eating fast foods (Western foods) such as spicy and salty foods is increasing among Asians. This kind of nutrition carries a heavy load of nitrate, which irreversiblyaffectsthe GI system. As our study showed, such effects are more probable to make GI erosions with higher frequency in the ERD subjects.

On the other hand, zinc deficiency is a common health problem in Asians. Zinc is an essential mineral in daily nourishment and plays a critical role in human tissue synthesis and repair. ${ }^{18}$

It has been shown that the essential nutrient zinc is highly concentrated in parietal cells (parietal cells are gastric cells that secrete gastric acid and intrinsic factor). So it may have beneficial effects on the treatment of gastric ulcers. ${ }^{13,19}$ Considers in the 1980 s examined zinc's capa- bility to mend and recover the defensive mucosal gel layer of the stomach. ${ }^{9}$

In addition zinc is rich in the muscularis of the gastric mucosa and appears to help this membrane to thicken. When the mucus membrane thickens it can better assist in buffering against excess gastric acid. It is known that zinc deficient patients are more susceptible to the development of gastric ulcers. Unfortunately proton pump inhibitors and H2-blockers inhibit the absorption of zinc, which may contribute to an unfortunate pathological cycle. ${ }^{15,18-19}$

Kirchhoff and colleagues, ${ }^{9}$ performed the first study to show the ability of zinc in the inhibition of acid secretion. They reported that zinc oral supplements (with or without PPIs) inhibited acid secretion and increased gastric $\mathrm{PH}$ in both human and rodent gastric glands. They showed that zinc delivered a fast and delayed hindrance of gastric corrosive discharge and offered a potential helpful contrasting option to PPIs. Similar to their findings, Tran and co-workers, ${ }^{20}$ presented that chronic gastritis could be constricted by fleeting treatment of zinc, which proposes that zinc alone might be powerful for the concealment of gastric mucosal irritation.

These results are not matched with our findings. We found a significant improvement of GERD presentations among all the subjects after 3 months treatment, which shows the strong effect of the same treatment in both groups (40 mg pantoprazole/daily and changing life style). However, there was no huge distinction between the results of the drug and the placebo groups, which shows the non-effective role of zinc supplementation on GERD's symptoms and severity. Similar to our results, Murphy and colleagues, ${ }^{10}$ reported that intake of anti-oxidants and minerals (such as vitamin $\mathrm{C}$ and $\mathrm{E}$, total carotenoids, zinc, copper, or selenium) had no effects on the symptoms of GERD or Barrett's esophagus.

Our findings showed that zinc supplementation cannot improve the severity of GERD. Other surveys should be performed to assess the impact of zinc supplementation on patients with GERD andzinc deficiency. Although considering zinc supplementation for GERD patients with underlying zinc deficiency would lead to better probable results, this element was not evaluated in our study before intervention.

It is also recommended to evaluate the relationship between other critical minerals and the severity of GERD to find other effective supplementations to replace or adjust 
the traditional treatment with PPIs and $\mathrm{H} 2$ blockers.

\section{ACKNOWLEDGEMENTS}

This manuscript is a part of an internist thesis. We would like to thank all members of Gastrointestinal and Liver Diseases Research Center (GLDRC) who assisted us in this study. We thank Dr. Zahra Haghparast Ghadim Limudahi for critical reading of the manuscript and for the insightful suggestions.

Funding/Support:

This study was supported by the Gastrointestinal and Liver diseases Research Center of Guilan University of Medical Sciences.

\section{CONFLICT OF INTEREST}

The authors declare no conflict of interest related to this work.

\section{REFERENCES}

1. Bashashati M, Hejazi RA, Andrews CN, Storr MA. Gasteroesophageal reflux symptoms not responding to proton pump inhibitor: GERD, NERD, NARD, esophageal hyper sensivity or dyspepsia? Can J Gasteroentrol Hepatol 2014;28:335-341.doi: $10.1155 / 2014 / 904707$

2. Wu YW, Tseng PH, Wang SY, Chiu HM, Tu CH, Wang HP, et al. Association of Esophageal Inflammation, Obesity and Gastro esophageal Reflux Disease: From FDG PET/CT Perspective. PLoS One 2014;9: e92001.doi: 10.1371/journal.pone.0092001.

3. Islami F, Pourshams A, Nasseri-Moghaddam S, Khademi H, Poutschi H,Khoshnia M, et al. Gastro esophageal Reflux Disease and overall and Causespecific Mortality: A Prospective Study of 50000 Individuals. Middle East J Dig Dis 2014;6: 65-80.

4. Liakakos T, Karamanolis G, Patapis P, P.Misiakos E. Gastero esophageal reflux disease: Medical or Surgical treatment? Gasteroentrol Res Pract 2009;371580:15. doi: $10.1155 / 2009 / 371580$

5. Mansour-Ghanaei F, Joukar F, Atshani SM, Chagharvand S, SoutiF. The epidemiology of gastroesophageal reflux disease: a survey on the prevalence and the associated factors in a random sample of the general population in the Northern part of Iran. Int $J$ Mol Epidemiol Genet 2013;4:175-82.

6. 6. Fass R. Erosive esophagitis and nonerosive reflux disease (NERD): comparison of epidemiologic, physiologic, and therapeutic characteristics. $J$ Clin Gasteroentrol 2007;41:131-7. doi:10.1097/01. mcg.0000225631.07039.6d

7. Wesswlls KR, Brown KH. Estimating the Global
Prevalence of Zinc Deficiency: Results Based on Zinc Availability in National Food Supplies and the Prevalence of Stunting.PLoS One 2012;7: e50568. doi: 10.1371/journal.pone.0050568.

8. Bulbena O, Esplugues JV, Escolar G, Gil L, Navarro $\mathrm{C}$, Esplugues J. Zinc acexamate inhibits gastric acid and pepsinogen secretion in the rat. $J$ Pharm Pharmacol 1990;42:252-6. doi: 10.1111/j.20427158.1990.tb05402.x

9. Kirchhoff P, Socrates T, Sidani S, Duffy A, Breidthardt T, GrobC,et al. Zinc salts provide a novel, prolonged and rapid inhibition of gastric acid secretion. Am J Gastroenterol 2011;106:62-70. doi: 10.1038/ajg.2010.327.

10. Murphy SJ, Anderson LA, Ferguson HR, Johnston BT, Watson PR, McGuigan J, et al. Dietary antioxidant and mineral intake in human is associated with reduced risk of esophageal adenocarcinoma but not reflux esophagitis or Barrett's esophagus. J Nutr 2010;140:1757-63. doi: 10.3945/jn.110.124362.

11. Wu P, Zhao XU, Ai ZS, Sun HH, Chen Y, Jiang YX, et al. Dietary intake and risk for reflux esophagitis: a case-control study. Gasteroentrol Res Prac 2013;13:1-9. doi: 10.1155/2013/691026.

12. Shaw M, Dent J, Beebe T, Junghard O, Wiklud I, Lind T, et al. The reflux disease questionnaire: a measure for assessment of treatment response in clinical trials. Health Qual Life Outcomes 2008;6:31-7. doi: 10.1186/1477-7525-6-31.

13. Kerby DS. The simple difference formula: An approach to teaching nonparametric correlation. Comprehensive Psychol 2014;3:11-IT. doi: 10.2466/11.IT.3.1.

14. Mahdeva S, Raman MC, Ford AC, Axon AT, Goh KL, Moayyedi P. Gastroesophageal reflux is more prevalent in Western dyspeptics: a prospective comparison of British and South-East Asian patients with dyspepsia. Aliment Pharmacol Ther 2005;21:148390. doi: 10.1111/j.1365-2036.2005.02455.x.

15. Franciosa M, Mashimo H. Stretta radiofrequency treatment for GERD: a safe and effective modality. $A m \quad J$ Gastroenterol 2013;108:1654-5.doi. org/10.1155/2013/783815.

16. El-Serag HB, Sweet S, Winchester CC, Dent J. Update on the epidemiology of gastro-oesophageal reflux disease: a systematic review. Gut 2014;63:87180.doi: 10.1136/gutjnl-2012-304269.

17. Liang WT, Wang ZG, Wang F, Yang Y, Hu ZW, Liu JJ,et al. Long term outcomes of patients with refractory gasteroesophageal reflux disease following a minimally invasive endoscopic procedure: a prospective observational study.BMC Gastroentrol 2014;14:178-82. doi:10.1186/1471-230X-14-178.

18. Akhtar S. Zinc Status in South Asian Populations-an Update. J Health Popul Nutr 2013;31:139-49.doi: 10.3329/jhpn.v31i2.16378. 
19. Khayyatzadeh SS, Maghsoudi Z, Foroughi M, Askari G, Ghiasvand R. Dietary intake of Zinc, serum levels of Zinc and risk of gastric cancer: A review of studies. Adv Biomed Res 2015;4:118. doi: 10.4103/2277-9175.157849.

20. Tran CD, Campbell MAF, Kolev Y, Chamberlain S, Huynh HQ, Butler RN. Short-term zinc supplementation attenuates Helicobacterfelis-induced gastritis in the mouse. J Infect 2005;50:417-424.flux disease: A systematic review. Gut 2014;63:871-880. doi: 10.1136/gutjnl-2012-304269. 